\title{
Utilização de cactáceas do gênero Pereskia na alimentação humana em um município de Minas Gerais
}

\author{
Utilization of cacti of the genus Pereskia in the human diet in a municipality of Minas Gerais
}

\author{
Martha Elisa Ferreira de Almeida ${ }^{I^{*}}$ Angelita Duarte Corrêa ${ }^{\mathrm{I}}$
}

\section{RESUMO}

\begin{abstract}
O objetivo deste trabalho foi avaliar a utilização de cactáceas do gênero Pereskia na alimentação humana. A pesquisa foi realizada nos 1.525 domicílios da cidade de São Gonçalo do Abaeté (MG). Nessa cidade, onde foi aplicado o questionário socioeconômico e quanto ao uso alimentar desta planta, comumente chamada de ora-pro-nóbis, somente 25 domicílios possuíam plantas do gênero Pereskia. Em 22 domicílios, havia a presença da Pereskia grandifolia, em três, havia a de Pereskia aculeata $e$, em um, havia os dois tipos. A presença de nutrientes na ora-pro-nobis foi citada por $83,33 \%$ dos entrevistados, sendo que $33,37 \%$ citaram um consumo mensal. A planta foi citada por $66,67 \%$ dos entrevistados como importante no tratamento da anemia ferropriva, por $16,67 \%$, como agente terapêutico para o câncer, por $12,50 \%$, para prevenção ou tratamento da osteoporose e, por 8,33\%, para o tratamento da constipação intestinal. A classificação da orapro-nobis na categoria das hortaliças foi citada por $54,17 \%$ dos entrevistados. Concluiu-se que o resgate cultural do consumo desse tipo de planta poderá melhorar a condição nutricional e de renda das pessoas menos favorecidas economicamente, tanto no ambiente urbano quanto rural, de diferentes regiões do Brasil.
\end{abstract}

Palavras-chave: Pereskia, ora-pro-nobis, consumo alimentar, hortaliça.

\section{ABSTRACT}

The objective of this study was to evaluate the use of cacti of the genus Pereskia, for human consumption food. The study was conducted in 1.525 households in the city of São Gonçalo do Abaeté (MG). In this city where the socioeconomic questionnaire was applied regarding the dietary use of this plant, commonly referred to as ora-pro-nobis, only 25 of the households possessed plants of the genus Pereskia. In 22 households there was the presence of Pereskia grandifolia, in three households there was Pereskia aculeata, and one had both types. The presence of nutrients in the ora-pro-nobis was cited by $83.33 \%$ of respondents, where $33.37 \%$ cited monthly consumption. The plant was cited by $66.67 \%$ of the respondents as important in the treatment of iron deficiency anemia, by $16.67 \%$ as a therapeutic agent for cancer, by $12.50 \%$ for prevention or treatment of osteoporosis and $8.33 \%$ for the treatment of constipation. ora-pro-nobis was classified as a vegetable by $54.17 \%$ of respondents. It was concluded that the cultural revival of consumption of this type of plant may improve nutritional status and income of lower-class families in both urban and rural regions, from different regions of Brazil.

Key words: Pereskia, ora-pro-nobis, dietary consumption, vegetable.

\section{INTRODUÇÃO}

Atualmente vivencia-se o chamado período de transição nutricional, com um aumento na ingestão de alimentos gordurosos, refinados e ricos em açúcares e um baixo consumo de frutas e hortaliças, principalmente as não-convencionais (ROCHA et al., 2008). As hortaliças não-convencionais (taioba, orapro-nobis, serralha e mostarda) são uma alternativa alimentar e uma opção de diversificação cultural, na atividade agropecuária, sobretudo na agricultura familiar, para populações rurais e urbanas de baixa renda (ROCHA et al., 2008). Entretanto, a falta de informações

'Departamento de Química, Universidade Federal de Lavras (UFLA), 37200-000, Lavras, MG, Brasil. E-mail: martha.almeida@ufv.br. *Autor para correspondência. 
por parte da população quanto ao seu valor nutricional e o modo de preparo faz com que seu consumo seja reduzido (SOUZA et al., 2009).

A dieta pode adquirir maior valor nutricional em relação a vitaminas e minerais, além do fornecimento de fibras, quando as hortaliças não-convencionais são utilizadas (PINTO, 1998). Segundo KNUPP \& BARROS (2008), as frutas e hortaliças não-convencionais geralmente apresentam teores de minerais e proteínas significativamente maiores do que as plantas domesticadas, além de serem mais ricas em fibras e compostos com funções antioxidantes. Devido aos elevados teores de proteínas apresentados pelas cactáceas do gênero Pereskia, essa planta é denominada "carne de pobre” (ROCHA et al., 2008), pois já foi identificado na Pereskia aculeata um conteúdo proteico na matéria seca de 17,40\% (ALMEIDA FILHO \& CAMBRAIA, 1974) e 28,59\% (TAKEITI et al., 2009).

A ora-pro-nobis, que no latim significa “rogai por nós”, é uma planta que pertence ao reino Plantae, classe Magnoliopsida, ordem Caryophyllales, família Cactaceae e gênero Pereskia. A ora-pro-nobis, nome popular das espécies Pereskia aculeata Miller e Pereskia grandifolia Haword, embora tenha um alto potencial de utilização no conjunto das hortaliças não-convencionais, ainda é cultivada de forma marginal e rudimentar (KINUPP, 2006).

O objetivo deste estudo foi avaliar a utilização de cactáceas do gênero Pereskia, “carne de pobre”, na alimentação humana dos moradores de uma cidade de Minas Gerais.

\section{MATERIAL E MÉTODOS}

O levantamento foi realizado após a aprovação do Comitê de Ética do Centro Universitário de Patos de Minas (Unipam), protocolo n⿳丷ㅜ 108/10, no período de setembro a outubro de 2010, nos 1.525 domicílios (100\%) da cidade de São Gonçalo do Abaeté (MG), que é um município não minerador do estado de Minas Gerais, localizado na região do Alto São Francisco a uma altitude de 798 metros acima do nível do mar, com uma população de 5.993 habitantes (BRASIL, 2010). Naqueles domicílios que possuíam a ora-pro-nobis, foi solicitada a assinatura do Termo de Consentimento Livre e Esclarecido, baseado na resolução 196/96 antes da aplicação do questionário socioeconômico e do uso alimentício desta planta.

Após a leitura do corpus coletado, procedeuse à categorização das respostas obtidas. As unidades textuais do questionário foram enumeradas e agrupadas de acordo com algumas semelhanças entre as respostas obtidas. Os participantes foram denominados em ordem alfabética por E maiúsculo, seguida pela numeração arábica de 1 a 24. Considerou-se a amostra de 24 domicílios, uma vez que em um domicílio havia a presença dos dois tipos de Pereskia.

\section{RESULTADOS E DISCUSSÃO}

A idade média dos participantes foi de $53,67 \pm 17,31$ anos e o número médio de filhos era de 0,92, com um máximo de três filhos/família. Nessas residências, moravam em média 2,5 pessoas, sendo um máximo de quatro moradores. A maioria dos estudados possuía escolaridade da $1^{\text {a a }}$ 4 $^{\mathrm{a}}$ série e recebia de um a dois salários mínimos mensais (Tabela 1). As três famílias que tinham renda mensal $\geq 3$ salários mínimos ingeriam a ora-pro-nobis na frequência de uma vez/ mês $(n=2)$ e raramente $(n=1)$. Segundo RELVAS \& MENDONÇA (2006), a classe econômica a que o indivíduo pertence é um importante determinante do consumo alimentar, pois quanto maior for a renda maior será a tendência de ingestão de uma grande variedade de alimentos.

Foi observado que, em 22 quintais (1,44\% dos domicílios da cidade), havia a presença da Pereskia grandifolia, em três quintais (0,20\% dos domicílios da cidade) havia a Pereskia aculeata e, em um domicílio (0,07\%), havia estes dois tipos de Pereskia. TURRA et al. (2007) relatam que a Pereskia é um dos gêneros

Tabela 1 - Características socioeconômicas dos entrevistados. São Gonçalo do Abaeté - MG, 2010.

\begin{tabular}{lll}
\hline Características & $\mathrm{N}^{\mathrm{o}}$ & $\%$ \\
\hline Escolaridade & 2 & \\
Analfabeto & 14 & 5,33 \\
$1^{\mathrm{a}}$ a $4^{\mathrm{a}}$ série & 1 & 4,17 \\
$5^{\mathrm{a}}$ a $8^{\mathrm{a}}$ série & - & - \\
$2^{\underline{0}}$ grau incompleto & 4 & 16,67 \\
$2^{\underline{0}}$ grau completo & 1 & 4,17 \\
Superior incompleto & 2 & 8,33 \\
Superior completo & & \\
Renda mensal familiar (reais) & 9 & 37,50 \\
0 - 509,00 & 9 & 37,50 \\
510,00 - $1.019,00$ & 2 & 8,32 \\
$1.020,00$ - $1.529,00$ & 1 & 4,17 \\
$1.530,00$ - 2.039,00 & 1 & 4,17 \\
2.040,00 - 2.549,00 & 1 & 4,17 \\
$\geq 2.550,00$ & 1 & 4,17 \\
Autônomo & &
\end{tabular}

Salário mínimo de R\$ 510,00 na data da entrevista. 
menos evoluídos, com cerca de 25 espécies de cactos folheares, distribuídos nas regiões entre o Brasil e o México, entretanto, na cidade de São Gonçalo do Abaeté (MG), apenas duas espécies foram encontradas.

A espécie Pereskia grandifolia Haword, comumente denominada de Cacto Rosa, Ora-pronobis, Jumbeba e Rosa-Madeira, é uma planta vastamente distribuída do nordeste brasileiro ao Rio Grande do Sul (TURRA et al., 2007). Tanto as folhas quanto os frutos são utilizados na culinária do semiárido brasileiro (DUARTE \& HAYSASHI, 2005; TURRA et al., 2007). A espécie Pereskia aculeata Miller, comumente denominada de Trepadeira-Limão e Groselha-de-Barbados (DUARTE \& HAYSASHI, 2005), Groselha-da-América (ROSA \& SOUZA, 2003; ROCHA et al., 2008) e Lobrobo (ROCHA et al., 2008) é uma trepadeira arbustiva que ocorre principalmente em regiões áridas ou levemente áridas (DUARTE \& HAYSASHI, 2005). No sul da África, tem causado a infestação das matas, sendo sugerido a distribuição desta região para localidades das Américas (PATERSON et al., 2009) como os Estados Unidos da América (principalmente na região da Flórida) e o Brasil (TAKEITI et al. 2009), onde ocorre da Bahia ao Rio Grande do Sul (ROSA \& SOUZA, 2003; DUARTE \& HAYSASHI, 2005; TAKEITI et al., 2009). Na Índia, essa planta também já foi identificada (ALMEIDA FILHO \& CAMBRAIA, 1974). É conhecida popularmente como "planta de quintal” (SOUZA et al., 2009) e possui um desenvolvimento vegetativo durante o ano inteiro (ALMEIDA FILHO \& CAMBRAIA, 1974). Seu consumo ocorre principalmente nas antigas regiões mineradoras de Minas Gerais (ALBUQUERQUE et al., 1991; DIAS et al., 2005), embora seja utilizada em outras localidades de Minas Gerais e do Brasil. Na cidade avaliada, o seu consumo foi relatado como raramente por $66,67 \%$ dos entrevistados, com relatos de dois em dois meses, uma vez/semestre e uma vez/ano. O consumo mensal foi citado por 33,37\%, com relatos de ingestão de quatro vezes/mês, três vezes/mês e uma vez/mês.

Quando questionados sobre a presença de nutrientes na ora-pro-nobis, 16,67\% $(\mathrm{n}=4)$ disseram que a planta não os possuía. Os demais relataram que a planta era rica em nutrientes, mas somente $41,67 \%$ ( $n=10)$ sabiam conceituar nutrientes e alguns citaram que esta planta era rica em vitaminas $(n=7)$, ferro $(n=3)$, cálcio (n=2) e proteínas (n=1). PINTO (1998) e KNUPP \& BARROS (2008) destacaram o elevado teor de minerais destas hortaliças e sua importância na alimentação diária.

Foi relatado por 20,83\% (n=5) das famílias que o consumo da planta não ocorria por todos os membros. A pesquisada E2 relatou: “só eu como, pois tenho vergonha de oferecer o alimento” e a pesquisada
E13 relatou: "só eu como, pois os outros se souberem não comem porque dá baba”. SOUZA et al. (2009) sugerem que tal fato vem ocorrendo pela falta de informações sobre o valor nutricional de plantas como as cactáceas do gênero Pereskia. Segundo ROCHA et al. (2008), a ora-pro-nobis já foi bastante apreciada nas refeições familiares, entretanto está sendo esquecida ou desvalorizada pelo êxodo rural e o consumo de alimentos industrializados.

Segundo os participantes, a ora-pro-nobis vem sendo utilizada em várias receitas, principalmente depois de ter assistido a um programa televisivo (Terra de Minas da emissora Rede Globo) sobre o assunto, bem como após ficar sabendo do Festival do ora-pronobis que ocorre anualmente na cidade de Sabará (MG) e que já estava na sua 13a edição no ano de 2010. Essa planta foi citada por $91,67 \%(n=22)$ dos participantes como ingrediente de refogados, por $16,67 \%(n=4)$ nas saladas cruas e por $8,33 \%(n=2)$ em sopas. Na Malásia, a Pereskia bleo é consumida em sopas (ER et al., 2007). Seis participantes relataram consumir principalmente seus "brotos", uma vez que estes são mais saborosos. A participante E7 consumia a planta só na lua minguante, pois, na lua nova, ela é “forte e pinica”. A participante E21 relatou consumir quase todos os dias quando havia brotos. Segundo ela, a planta é forte e, quando a consumia, passava o dia todo bebendo água, o que era bom para a sua saúde. Algumas formas de preparo utilizando a ora-pro-nobis citadas foram: folhas empanadas no fubá (E4); no omelete e com costelinha de porco (E6); no omelete e picada fina no molho do macarrão (E9); no omelete e associada ao suco de couve (E13); associada ao suco de laranja, acerola e couve (E14); na salada de couve ou taioba (E15) e no bambá de couve (E19). As principais combinações de pratos citadas foram: arroz, feijão e angu (E2); com angu, pois ela é "boa igual quiabo" (E3); angu e farofa (E4); arroz, feijão e salada (E5); costelinha, frango e no meio da salada “para achar que é couve” (E6); arroz (E7 e E24); arroz, feijão, frango e polenta (E8); omelete e salada (E9); arroz, feijão e carne (E10); arroz, feijão, carne e ovos (E13); arroz e salada (E14); frango e angu (E15); arroz, feijão, macarrão, frango e carne (E16); jiló, macarrão e frango (E17); arroz, feijão e angu (E18); frango (E20); arroz e angu (E21); arroz, feijão, carne, frango e angu (E22). FIDÉLIX et al. (2010) relatam que as folhas podem enriquecer o arroz com o feijão, bem como tornar estas preparações mais atraentes através da cor verde.

O alto conteúdo proteico e de fibras do tipo mucilagens da Pereskia aculeata (MERCÊ et al., 2001a; ROSA \& SOUZA, 2003; DUARTE \& HAYASHI, 2005; FIDÉLIX et al., 2010) e a ausência de toxicidade de suas folhas, as tornam importantes na alimentação 
humana (na forma de sopas, refogados, mexidos, omeletes, saladas, biscoito doce e torta salgada) e animal (ROSA \& SOUZA, 2003; DIAS et al., 2005; DUARTE \& HAYASHI, 2005; TAKEITI et al., 2009). ROCHA et al. (2008) destacam a presença dessa planta em preparações como farinhas, saladas, refogados, tortas e na indústria alimentícia, já tendo sido desenvolvida e aprovada, com um índice de aceitabilidade $>70 \%$, uma massa de macarrão do tipo talharim adicionado de ora-pro-nobis desidratada. A presença dos arabinogalactanas e galactomanas poderá ser importante não só na indústria alimentícia como também na farmacêutica (MERCÊ et al., 2001a,b). THOMAS et al. (1987) isolaram nesta espécie o sitosterol e o estigmasterol, que poderão ser utilizados na indústria de margarinas, uma vez que estes compostos apresentam a capacidade funcional de reduzir os níveis de LDL-colesterol (RODRIGUES et al., 2004).

A ora-pro-nobis, denominada Pereskia grandifolia, não foi estudada quanto a sua composição centesimal e mineral.

A ora-pro-nobis foi citada por 66,67\% dos entrevistados para o tratamento da anemia ferropriva, pois eles a consideram "forte”, ou seja, rica em ferro. Segundo a Organização Mundial de Saúde (OMS), 20 a 30\% da população mundial adulta apresentam anemia ferropriva (RODRIGUES \& JORGE, 2010). SILVA \& PINTO (2006) e TAKEITI et al. (2009) encontraram nas folhas de Pereskia aculeata teor de ferro de 14,18 e 28,12mg $100 \mathrm{~g}^{-1}$ de matéria seca, respectivamente. Quando se compara o nível observado por SILVA \& PINTO (2006) com alimentos em 100g de matéria seca descritos na Tabela Brasileira de Composição de Alimentos (TACO, 2006), pode ser destacado que o teor de ferro da ora-pro-nobis foi superior a vários alimentos referidos popularmente como fonte de ferro, como: beterraba crua $(1,43 \mathrm{mg})$ e cozida $(2,13 \mathrm{mg})$, couve manteiga refogada $(2,70 \mathrm{mg})$, espinafre refogado (4,48mg), fígado bovino grelhado (12,89mg), grão de bico cru (6,16mg), lentilha crua (7,91mg) e vários tipos de feijões crus (fradinho - 5,84mg; preto - 7,64mg; roxo-7,89mg e carioca-9,30mg).

A ora-pro-nobis foi relatada por 16,67\% como importante agente terapêutico para o câncer. Segundo a entrevistada E15, seu marido utilizou diariamente a Pereskia aculeata por indicação médica durante dois anos, como agente terapêutico para o câncer, e sua mãe também utilizou esta planta para melhorar os níveis de plaquetas, uma vez que possuía leucemia. A pesquisada E2 relatou consumir a Pereskia grandifolia para aumentar os níveis de plaquetas, por indicação médica. Na Malásia, as folhas da Pereskia grandifolia são utilizadas no tratamento do câncer, hipertensão arterial, diabetes mellitus e doenças associadas ao reumatismo e inflamação, dor de cabeça, dermatite atópica e hemorroidas (SIM et al., 2010). A Pereskia bleo na Malásia é considerada uma planta medicinal com atividade antitumoral (ER et al., 2007; TURRA et al., 2007). Na Pereskia grandifolia, a vitamina E fitona e o 2,4-ditert-butilfenol (SRI NURESTRI et al., 2009) e na Pereskia bleo os compostos dihidroactinidiolide, 2,4-ditert-butilfenol, $\alpha$ tocopherol e fitol (SRI NURESTRI et al., 2008), apresentaram efeito citotóxico sobre as células carcinomas epidermoides nasofaríngea humana (KB), carcinoma cervical humano (CasKi), carcinoma do cólon humano (HCT116), carcinoma mamário dependente de hormônio (MCF7) e carcinoma de pulmão humano (A549). TAN et al. (2005) observaram significante atividade citotóxica das folhas de Pereskia bleo sobre as linhagens T47D. ER et al. (2007) observaram que o extrato aquoso e metanólico das folhas de Pereskia bleo não apresentaram efeito significativo antiproliferativo contra as células neoplásicas mamárias de ratos (4T1), não sendo condizente com o argumento utilizado por comunidades da Malásia, em que as folhas são utilizadas para o tratamento do câncer.

A planta foi citada por $12,50 \%$ dos participantes como importante para a prevenção ou tratamento da osteoporose e por 8,33\% para o tratamento da constipação intestinal. Também houve a citação do consumo para o controle de infecções pulmonares e generalizadas e como cicatrizante. Desde a antiguidade, as cactáceas têm sido utilizadas na medicina tradicional, sendo que os indígenas ainda as utilizam como antibióticos, analgésicos, diuréticos, no controle de infecções cardíacas e nervosas, no combate a diarreia, queimaduras, cicatrização de úlceras, no controle do diabetes mellitus e das dislipidemias e como fonte de vitaminas e minerais (HOLLIS \& SCHEINVAR, 1995). A partir dos relatos da importância da planta, foi questionado sobre o tempo de plantio, quem e por que a plantou? Foi relatado por $37,50 \%$ que não sabiam a idade da planta, mas que a tinha há muito tempo no quintal, sendo que $62,50 \%$ relataram a idade da planta, com uma média de 9,87 anos. Aidade mínima de plantio destas cactáceas foi de dois anos e máxima de 35 anos. A metade dos participantes do estudo (50,00\%) disse que a tinha plantado alegando "que era boa e que servia como remédio”, "para tratamento de anemia e constipação intestinal”, "funciona como cerca viva” e “produzia belas flores”. DUARTE \& HAYSASHI (2005) e TURRA et al. (2007) destacam que as cactáceas do 
gênero Pereskia têm sido cultivadas como planta ornamental devido à beleza de suas flores.

Ao ser questionado se a ora-pro-nobis era uma hortaliça, 45,83\% dos entrevistados disseram que a planta não se enquadrava nesta categoria, conforme os relatos: “dá em quintal, pois é planta grande” (E2); “pertence à planta grande de quintal” (E10); “não pertence, pois tem espinhos grandes” (E11); “não requer cuidados como requer uma horta” (E15); “não é de horta não, é de quintal e se plantar na horta fica grande e dá muito espinho” (E2). A classificação da ora-pro-nobis na categoria das hortaliças foi citada por $54,17 \%$, conforme os relatos: "pelo gosto parecido com a couve” (E3 e E22); "tem vitamina igual à couve” (E5); "porque é boa para anemia, contém ferro” (E6); "serve de remédio" (E7); "sabe que ganhou no prato típico, visto na TV” (E8); “é uma planta de que se come a folha” (E14); “ela serve de verdura de mistura” (E21).

\section{CONCLUSÃO}

Conclui-se que o consumo da ora-pronobis, também denominada de "carne de pobre”, foi associado principalmente ao tratamento da anemia ferropriva, câncer, osteoporose e à constipação intestinal. O resgate cultural do consumo deste tipo de planta pela população brasileira poderá melhorar a condição nutricional e de renda de pessoas menos favorecidas economicamente, tanto no ambiente urbano quanto rural, de diferentes regiões do Brasil, principalmente naquelas em que o clima e o solo são mais adaptados para o cultivo destas cactáceas conhecidas como hortaliças não-convencionais.

\section{REFERÊNCIAS}

ALBUQUERQUE, M.G.P.T. et al. Composição centesimal e escore de amino-ácidos em três espécies de "ora-pro-nobis" (Pereskia aculeata Mill., P. bleu De Candolle e P. pereskia (L) Karsten). Boletim SBCTA, v.25, n.1, p.7-12, 1991.

ALMEIDA FILHO, J.; CAMBRAIA, J. Estudo do valor nutritivo do ora-pro-nobis (Pereskia aculeata Mill.). Revista Ceres, v.21, n.114, p.105-111, 1974.

BRASIL. Dados do Censo 2010 publicados no Diário Oficial da União do dia 04/11/2010. Disponível em: <http:/ /www.ibge.gov.br/censo 2010 /dados_divulgados/ index.php?uf=31>. Acesso em: 01 fev. 2011.

DIAS, A.C.P. et al. Avaliação do consumo de hortaliças não convencionais pelos usuários das Unidades do Programa Saúde da Família (PSF) de Diamantina - MG. Alimentos e Nutrição, v.16, n.3, p.279-284, 2005. Disponível em: <http://servbib.fcfar.unesp.br/seer/index.php/alimentos/article/viewFile/481/ 447>. Acesso em: 12 dez. 2011.
DUARTE, M.R.; HAYASHI, S.S. Estudo anatômico de folha e caule de Pereskia aculeata Mill. (Cactaceae). Revista Brasileira de Farmacognosia, v.15, n.2, p.103-109, 2005. Disponível em: <http://www.scielo.br/scielo.php?pid=S0102695X2005000200006\&script=sci_arttext $>$. Acesso em: 12 dez. 2011. doi:10.1590/S0102-695X2005000200006.

ER, H.M. et al. Anti-proliferative and mutagenic activities of aqueous and methanol extracts of leaves from Pereskia bleo (Kunt) DC (Cactaceae). Journal of Ethnopharmacology, v.113, n.3, p.448-456, 2007. Disponível em: <http:// w w w. sciencedirect.com/science/article/pi i / S0378874107003236>. Acesso em: 12 dez. 2011. doi: 10.1016/ j.jep.2007.06.026

FIDÉLIX, M.P. et al. Estudo experimental sobre as características nutricionais e sensoriais do ora-pro-nobis (Pereskia aculeata Mill). Nutrição Brasil, v.9, n.6, p.392397, 2010.

HOLLIS, H.B.; SCHEINVAR, L. El interesante mundo de las cactáceas. Cidad del México: Fundo de Cultura Econômica, 1995. 235p.

KINUPP, V.F. Plantas alimentícias alternativas no Brasil: uma fonte complementar de alimento e renda. Revista Brasileira de Agroecologia, v.1, n.1, p.333-336, 2006. Disponível em: <http://www.aba-agroecologia.org.br/ojs2/index.php/cad/article/ view/1524>. Acesso em: 12 dez. 2011.

KINUPP, V.F.; BARROS, I.B.I. Teores de proteína e minerais de espécies nativas, potenciais hortaliças e frutas. Ciência e Tecnologia de Alimentos, v.28, n.4, p.846-857, 2008. Disponível em: <http:/ /www.scielo.br/scielo.php?script=sci_arttext\&pid=S010120612008000400013\&lng=pt\&nrm=iso>. Acesso em: $12 \mathrm{dez} .2011$. doi: 10.1590/S0101-20612008000400013.

MERCÊ, A.L.R. et al. Complexes of arabinogalactan of Pereskia aculeata and $\mathrm{Co}^{2+}, \mathrm{Cu}^{2+}, \mathrm{Mn}^{2+}$, and $\mathrm{Ni}^{2+}$. Bioresource Techonology, v.76, n.1, p.29-37, 2001a. Disponível em: <http://www.sciencedirect.com/science/article/pii/ S096085240000078X>. Acesso em: $12 \mathrm{dez}$. 2011. doi: 10.1016/S0980-8524(00)00078-X.

MERCÊ, A.L.R. et al. Fe(III) - Galactomannan solid and aqueous complexes. Potentiometric, EPR spectroscopy and thermal data. Journal of Brazilian Chemical Society, v.12, n.6, p.791-798, 2001b. Disponível em: <http:// w w w. s c i e l o.b r / s c i e lo.ph p ? p i d = S 0103 50532001000600017\&script $=$ sci_abstract $>$. Acesso em: 12 dez. 2011. doi: 10.1590/S0103-50532001000600017.

PATERSON, I.D. et al. Using molecular methods to determine the origin of weed populations or Pereskia aculeate in South Africa and its relevance to biological control. Biological Control, v.48, n.1, p.84-91, 2009. Disponível em: <http:// w w w. sciencedirect.com/science / a r t i c le / pi i / S1049964408002533>. Acesso em: 12 dez. 2011. doi: 10.1016/ j.biocontrol.2008.09.012.

PINTO, N.A.V.D. Avaliação das folhas, limbos e caules da taioba (Xanthosoma sagittifolium Schott), visando seu aproveitamento na alimentação humana. 1998. $89 \mathrm{f}$. Dissertação (Mestrado em Ciência dos Alimentos) - Universidade Federal de Lavras, Lavras, MG. 
RELVAS, K.; MENDONÇA, P.S.M. Hábitos de compra e consumo de alimentos de idosos nas cidades de São Paulo, Porto Alegre, Goiânia, Recife. 2006. 119f. Dissertação (Mestrado em Agronegócio) - Universidade Federal de Mato Grosso do Sul, Campo Grande, MS.

ROCHA, D.R.C. et al. Macarrão adicionado de ora-pro-nobis (Pereskia aculeata Miller) desidratado. Alimentos e Nutrição, v.19, n.4, p.459-465, 2008. Disponível em: <http://servbib.fcfar.unesp.br/seer/index.php/alimentos/article/viewFile/656/ 552>. Acesso em: 12 dez. 2011.

RODRIGUES, J.N. et al. Caracterização físico-química de creme vegetal enriquecido com ésteres de fitosteróis. Revista Brasileira de Ciências Farmacêuticas, v.40, n.4, p.505-520, out./dez. 2004. Disponível em: <http://www.scielo.br/scielo.php?pid=S151693322004000400008\&script $=$ sci_abstract\&tlng=pt $>$. Acesso em: 12 dez. 2011. doi: 10.1590/S1516-93322004000400008.

RODRIGUES, L.P.; JORGE, S.R.P.F. Deficiência de ferro na mulher adulta. Revista Brasileira de Hematologia e Hemoterapia, v.32, Supl.2, p.49-52, 2010. Disponível em: $<$ ht tp: //www.scielo.br/scielo.php?pid=S 1516 84842010000800010\&script=sci_arttext $>$. Acesso em: $12 \mathrm{dez}$. 2011. doi: 10.1590/S1516-84842010005000059.

ROSA, S.M.; SOUZA, L.A. Morfo-anatomia do fruto (hipanto, pericarpo e semente) em desenvolvimento de Pereskia aculeata Miller (Cactaceae). Acta Scientarium Biological Sciences, v.25, n.2, p.415-428, 2003. Disponível em: <http:// periodicos.uem.br/ojs/index.php/ActaSciBiolSci/article/view/ 2046/1508>. Acesso em: 12 dez. 2011. doi: 10.4025/ actascibiolsci.v25i2.2046.

SILVA, M.C.; PINTO, N.A.V.D. Teores de nutrientes nas folhas de taioba, ora-pro-nóbis, serralha e mostarda coletadas no município de Diamantina. In: FUNDAÇÃO EDUCACIONAL CIENTÍFICA E TECNOLOGIA DA UFVJA, 8., 2006, Diamantina, MG. Anais... Diamantina: editora UFVJA, 2006. 124p.

SIM, K.S. et al. Acute oral toxicity of Pereskia bleo and Pereskia grandifolia in mice. Pharmacognosy Magazine, v.6, n.21, p.67-70, 2010. Acesso: <http://www.phcog.com/ article. asp? issn $=0973-1296$; year $=2010 ;$ volume $=6$; issu $\mathrm{e}=21$; spage=67; epage=70; aulast=Sim $>$. Acesso em: $12 \mathrm{dez}$. 2011. doi: 10.4103/0973-1296.59969.

SOUZA, M.R.R. et al. O potencial do ora-pro-nobis na diversificação da produção agrícola familiar. Revista Brasileira de Agroecologia, v.4, n.2, p.3550-3554, 2009. Disponível em: <http://www.aba-agroecologia.org.br/ojs2/index.php/cad/ article/view/4776>. Acesso em: 12 dez. 2011.

SRI NURESTRI, A.M. et al. Cytotoxic activity of Pereskia bleo (Cactaceae) against selected human cell lines. International Journal of Cancer Research., v.4, n.1, p.2027, 2008. Disponível em: <http://scialert.net/ qredirect.php?doi=ijcr.2010.180.187\&linkid=pdf $>$. Acesso em: 12 dez. 2011. 10.3923/ijcr.2010.180.187.

SRI NURESTRI, A.M.S. et al. Phytochemical and cytotoxic investigations of Pereskia grandifolia Haw. (Cactaceae) leaves. Journal of Biological Sciences, v.9, n.5, p.488-493, 2009. Disponível em: <http://scialert.net/ qredirect.php?doi=jbs.2009.488.493\&linkid=pdf $>$. Acesso em: 12 dez. 2011. doi: 10.3923/jbs.2009.488.493.

TACO. Tabela de composição de alimentos/NEPAUNICAMP. 2.ed. Campinas: NEPA-UNICAMP, 2006. 114p. Disponível em: <http://www.unicamp.br/nepa/taco/contar/ taco_versao2.pdf>. Acesso em: 17 maio, 2010.

TAKEITI, C.Y. et al. Nutritive evaluation of non-conventional leafy vegetable (Pereskia aculeata Miller). International Journal of Food Sciences and Nutrition, v.60, n.1, p.148160, 2009.

TAN, M.L. et al. Methanolic extract of Pereskia bleo (Kunth) DC. (Cactaceae) induces apoptosis in breast carcinoma, T47D cell line. Journal of Ethnopharmacology, v.96, n.1, p.287294, 2005. Disponível em: <http://www.sciencedirect.com/ science/article/pii/S037887410400460X>. Acesso em: $12 \mathrm{dez}$. 2011. doi: 10.1016/j.jep.2004.09.025.

THOMAS, A.S. et al. Dominance of delta-5-sterols in eight species of Cactaceae. Phytochemistry, v.26, n.3, p.731733, 1987. Disponível em: <http://www.sciencedirect.com/ science/article/pii/S0031942200847743>. Acesso em: $12 \mathrm{dez}$. 2011. doi: 10.1016/S0031-9422(00)84774-3.

TURRA, A.F. et al. Avaliação das propriedades antioxidantes e susceptibilidade antimicrobiana de Pereskia grandifolia Haworth (Cactaceae). Arquivos de Ciências da Saúde da Unipar, v.11, n.1, p.9-14, $2007 . \quad$ Disponível em: <http:// revistas.unipar.br/saude/article/view/978/852>. Acesso em: 12 dez. 2011. 